\title{
Study on the Innovational Function of the Management
}

\author{
Yun Zhang \\ Department of Industrial and Commercial Management, Nanjing Institute of Industry Technology \\ Nanjing 210046, China \\ E-mail: rossa0897@sina.com
}

\begin{abstract}
Traditional management process summarization should be improved in adapting and instructing the diversified management for modern enterprises, and Chinese enterprises at the present stage also urgently need the new understanding for the management function. Starting from the cognition and practice of the management, the innovation should be the core function of the management, and it should be embodied in the function of the management.

Keywords: Innovation, Function, Management, Process

Four functions such as planning, organizing, leading and controlling in the management are the mainline in the management theory all along. Traditional management scholars thought that all managers in all departments and all classes in the enterprise would carry out these functions, and effective management meant to complete these functions successfully. Robbins thought that "the actual management is not so simple like described management function, and there are not simple, limit-clear and pure starts and terminals of planning, organizing, leading and controlling in the real world". We think the innovation runs through the process of the management, and it should be the core function of the management.
\end{abstract}

\section{Understanding the innovational function of the management}

The innovational function of the management can be understood as that the change of exterior environment threatens the survival and running of the system to certain extent, and to avoid the system loss induced by the threat or its extension, the system develops the local or whole adjustment in the interior, or predict the opportunity which is helpful for the system development in the environment when the system observes or experiences the changes in the exterior world, and actively adjust the strategy and technology of the system to actively develop and utilize the opportunity to seek the development of the system. Because of the multiplicity and levity of the threat and opportunity, the innovation should not be institutionalized, and the system has not copy gifted entrepreneurs all along, but the innovational entrepreneur emerges continually. With the development of productivity and the advancement of the technology, the innovational function of the management gradually possesses the natures of recognition and practice.

\subsection{The recognition of the innovational function}

In the management function system, some scholars put forward the hierarchy function structure, and the macro function includes planning, decision-making, evaluating, predicting and other defensive functions, and the basic function includes planning, organizing, controlling, leading, commanding, harmonizing and encouraging for general management problems, and the micro function includes many sub-functions such as investigating, researching, analyzing, processing, preparing, propagandizing, training, ordering, appointing and removing, inducting, consulting, deploying, implementing, censoring, checking, summarizing and rewarding and publishing, which is used to prefect and supply the basic function and the macro function. In above three layers including 28 functions, the innovation is not listed. We think that the innovation exists in every function, and especially for the macro function and the basic function, the innovation will decide the result and efficiency of the management to the largest extent.

\subsection{The practice of the innovational function}

Many successful enterprises generally adopt the mode of encouragement management, and form the innovation culture of the enterprise. Toyota Motor Corp alleged that their employees would propose 200 million new ideas every year, and each employee would put forward 35 advices averagely, and $85 \%$ of these advices would be adopted by the company. In the daily management of Microsoft Corporation, the work time could be changed flexibly. Program design is a sort of research work with innovations and highly centralized energies, so the researchers and designers need comfortable feelings to complete their works consciously. Someone may select working in the night, and be on duty at 22 o'clock and off duty at 6 o'clock in the next day. To keep intensive and comfortable work atmosphere, the company divides employees into many group with $5 \sim 15$ persons to engage in the research and development of the project. Designers all 
work for a long time, and they input program to the computer ceaselessly all day and print paper pile, and the work rhythm is so quick to make people crazy. Employees consciously delay the work time, and no one wants to be the person who first leaves the office. The work atmosphere forms loose and devoted work principles, and makes the work efficiency of Microsoft Corporation extraordinarily high. The innovational representation of the successful enterprise is the exertion and embodiment of the innovation of the whole enterprise, and the support and perfection of the innovational function is the activator to enhance the competitive force and efficiency of the enterprise.

\section{The innovational function is the core function of the management}

\subsection{Necessary innovational function}

In the management process, only to maintain the order is not enough, and once the management system is closed, the system can but spontaneously go to disorder. As viewed from the entropy theory and the dissipative structure theory, the negative and isolated maintenance is entropy production, and the essential of innovation and reform is negative entropy which is the necessary condition for the system evolvement. Without the innovation but the maintenance, the entropy production in the system can not maintain the order state, and without the maintenance but the innovation, the system will be in the non-balanced state for ever. Only the management with the optimized combination of maintenance and innovation is the excellent management. Peter Drueker thought that "the deficiency of innovation is the biggest single reason for the ruin of existing organization". In the future, the innovation of the organization and society is same important with the innovation of the technology. Only if the maintenance matches with the innovation and the speed and quality of the innovation is good enough, the enterprise or any human system in the competition could survive and develop healthily.

\subsection{Innovational function represents its values in other functional activities}

Various management functions have their own special representation form. The function of planning is embodied by confirming objective, establishing strategy and developing the layout, project or plan of the sub-plans. The function of organizing is embodied by the organization structure design and personnel distribution. The function of leading is embodied by the leaders' instructing and encouragement, and solving conflicts. The function of controlling is embodied by monitoring the activity process to ensure the information feedback and measure correction completed by the plan. If the environment doesn't change and renovate, the plan will be invariable, and all organizations will sustain good structure design, and the decision-making project will be confirmed because of the exact prediction of the result. However, the environment always changes, managers should deal with challenges at any moment, and in each stage and every function of the management activity, they should innovate everywhere at every turn and at any time. The innovational function happens not only in the term of strategic layout decision-making, but in the daily management, so it has not special representation form, and it represents its survival and values in all activities of other management functions. In the continually changing environment, the objective, content, form and activity factors of the system activity must continually change and adjust it, or else, the interior factors of the management system will be impacted even eliminated. Therefore, the innovation will be picked out from four functions of the management, and be the core function of the management.

\section{Innovational contents in the management process}

\subsection{The Innovation in the planning function}

Some most important strategies in the organization always occur when you least expect them to, which can not be knew by the senior managers before. To fully utilize these strategies, we usually need to identify them and expand their influences. For example, some new purposes found by some salesman occasionally could be turned into the new major operation of the corporation. Planners always look for modes in the failed experiment, seemly random activity or disorder learning, and they usually could find the new methods to solve the problem or consider the problem, for example, finding the new market which doesn't get in, or understanding the characteristics of the corresponding new product, and so on.

\subsection{The innovation in the organizational function}

Because increasing competition, the requirement of the enterprise to the innovation is higher and higher, and many enterprises are implementing reforming actively and flow construction, and trying to be learning-type organizations. Modern management theories thought that the organization innovation was the composing of the "technical" advancement and the investment of the management system and structure in the production, distribution and sale was the composing of the total capitals.

\subsection{The innovation in the leading function}

The result of leading is to induce the reform, usually the drastic reform, and form very active reforming potential, which requires that leaders must accept continual challenges and innovations, and make the enterprise be in the advantaged competitive status through actively reform. 


\subsection{The innovation in the control function}

Joseph Alois Schumpeter emphasized that "the innovation of the enterprise is the drive of the economic development". The intention of the management control is to test whether the system is running normally and developing according to the strategic objective. The innovation in the management control function is also embodied in the project manage of the total lifecycle and total system, and in the total system and total process quality management and control.

The innovation is not listed as a sort of management function, and it is related to the industrial development level in the initial development stage of the management theory. With the quick development, levity and uncertain of the scientific technology, every manager will encounter new situation and new problems every day. The conformism can not deal with new challenges, and without the innovation, the enterprise can not sustain the operation and acquire ideal management performance. The drastic competition and challenges of the globalization compel managers to make the innovation in the management process as a sort of core function. In Gottlieb Guntern's book, he pointed out that "the proper combination of sufficient innovation speed and quality is the first key factor to acquire the success". In the further research, we should mainly emphasize the content embodiment of the innovational function and how to embody these contents.

\section{References}

Gottlieb Guntern. (2000). Challenges of Innovational Lead. Beijing: Tsinghua University Press.

Huang, Renjie. (2007). Contents and Methods of the Enterprise Management Innovation. Modern Management Science, No.1, P. 79-81.

Zhang, Wei. (2001). New Innovational Management in New Economic Times: Innovational Management of the Complex Product System. Economic Management, No.16, P. 69-75.

Zhou, Sanduo. (2000). Management Theory. Beijing: Higher Education Press. April of 2000. 